University of Nebraska - Lincoln

DigitalCommons@University of Nebraska - Lincoln

1998

\title{
On the Proper Definition of Cognitive Ethology
}

\author{
Alan Kamil \\ University of Nebraska - Lincoln, akamil1@unl.edu
}

Follow this and additional works at: https://digitalcommons.unl.edu/bioscibehavior

Part of the Behavior and Ethology Commons

Kamil, Alan, "On the Proper Definition of Cognitive Ethology" (1998). Papers in Behavior and Biological Sciences. 18.

https://digitalcommons.unl.edu/bioscibehavior/18

This Article is brought to you for free and open access by the Papers in the Biological Sciences at DigitalCommons@University of Nebraska - Lincoln. It has been accepted for inclusion in Papers in Behavior and Biological Sciences by an authorized administrator of DigitalCommons@University of Nebraska - Lincoln. 
Published (as Chapter 1) in Animal Cognition in Nature: The Convergence of Psychology and Biology in Laboratory and Field, edited by Russell P. Balda, Irene M. Pepperberg, and Alan C. Kamil, San Diego (Academic Press, 1998), pp. 1-28. Copyright (c) 1998 by Academic Press. Used by permission.

\title{
On the Proper Definition of Cognitive Ethology
}

\author{
Alan C. Kamil
}

School of Biological Sciences and Department of Psychology, Nebraska Behavioral Biology Group, University of Nebraska-Lincoln, Lincoln, NE 68588-0118, USA

$\begin{array}{lr}\text { Introduction } & 1 \\ \text { Scientific progress } & 1 \\ \text { The cognitive research program } & 3 \\ \text { Reasons for fragmentation } & 4 \\ \text { Current state of affairs } & 6 \\ \text { The ethological program } & 6 \\ \text { Synthesis } & 7 \\ \text { Conclusions } & 21 \\ \text { Acknowledgements } & 23 \\ \text { References } & 23\end{array}$

\section{Introduction}

The last 20-30 years have seen two "scientific revolutions" in the study of animal behavior: the cognitive revolution that originated in psychology, and the Darwinian, behavioral ecology revolution that originated in biology. Among psychologists, the cognitive revolution has had enormous impact. Similarly, among biologists, the Darwinian revolution has had enormous impact. The major theme of this chapter is that these two scientific research programs need to be combined into a single approach, simultaneously cognitive and Darwinian, and that this single approach is most appropriately called cognitive ethology.

\section{Scientific progress}

What constitutes progress in science? At one level, there is substantial agreement: progress consists of the testing of specific alternative hypotheses that results in the rejection of most of these hypotheses. It can be argued that, in the long run, all will be rejected. This is the concept of falsification, perhaps best ex- 
pressed for the working scientist by the process called strong inference (Platt, 1964), in which multiple hypotheses are generated and experiments designed to disprove as many of them as possible.

However, at another level, the falsificationist position is incorrect. Major high-level theories, such, as those of Newtonian physics, Ptolemaic astronomy, Lorenzian ethology or radical behaviorism are not rejected on the basis of one, or even a few, facts or experiments that are inconsistent with them. The process of strong inference does not apply with hypotheses/theories at this level of generality.

Some philosophers (e.g. Kuhn, 1970; Lakatos, 1974) have provided alternative accounts of how scientific progress occurs at these levels. The work of Kuhn is particularly familiar to many scientists. In his book titled The Structure of Scientific Revolutions, Kuhn (1970) argued that the falsificationist view is incorrect, demonstrating that changes in broad theories, which he called scientific paradigms, do not occur according to the falsificationist model. Unfortunately, Kuhn failed to specify clearly how the process of change from one paradigm to another, or scientific revolution in his words, takes place. Kuhn makes it sound like a generational or sociological phenomenon, not necessarily related to data at all.

Another philosopher of science, less well known outside philosophical circles, Imre Lakatos (1974), has extended the arguments of Kuhn in a particularly useful way, providing a cogent analysis of how paradigmatic changes that do address the issue of the relationship between broad scientific theories and data take place. Lakatos argues that science is characterized by what he calls research programs, roughly equivalent to Kuhn's scientific paradigms. A research program consists of two parts: a central "hard core" and a protective belt of specific auxiliary hypotheses. The central core consists of definitions and assumptions that coherently map out directions for research, but this core is not subject to direct test. Instead, the auxiliary hypotheses are used to derive specific models and hypotheses, which are subject to empirical test, revision and rejection.

Lakatos uses an amusing fictional anecdote to illustrate the difference between the hard core of a research program and its surrounding web of auxiliary hypotheses. Imagine a pre-Einsteinian physicist who uses the central core of his scientific program, Newton's mechanics and the law of gravity, to calculate the path of a newly discovered planet, $p$. However, observation of the planet shows that its orbit deviates from the predicted one. Does the physicist abandon Newtonian physics? No. He revises his auxiliary hypotheses, and calculates that there is another, previously unknown planet, $\mathrm{p}^{\prime}$, which disturbs the orbit of $\mathrm{p}$. This is a new model, which is subjected to test by building a large new telescope to look for $\mathrm{p}^{\prime}$. Suppose $\mathrm{p}^{\prime}$ is found. It would be considered a great victory for Newtonian physics. Why? - because it would be the discovery of a new, previously unexpected fact, implying that Newtonian physics was a progressive research program. But suppose $\mathrm{p}^{\prime}$ was not observed. The physicist would still not abandon the central core of Newtonian physics. He might modify his 
model again, predicting that there is a cloud of dust located so as to obscure the view of supposed planet $\mathrm{p}^{\prime}$. This new model could then be tested by sending a satellite to collect data to determine if the cloud of dust existed, and so on.

So how does change from one scientific research program to another take place? Lakatos distinguishes two types of programs: degenerate and progressive. A progressive program is one that is resulting in the discovery of new, previously unknown facts. It may also be able to explain facts long known but previously not understood. In contrast, a degenerate program is one that is not producing new discoveries, but only reiterating old ones. Given a choice between these two types of programs, Lakatos argues, most scientists will choose the exciting, progressive program over the dull, degenerate program. The major advantage of Lakatos' approach over Kuhn's is that the formulation of Lakatos specifies a relationship between evidence and scientific revolutions. The paradigm or research program that is leading to exciting new discoveries is the one that will prevail.

This approach to understanding scientific progress suggests that science progresses in two ways. A specific research program is developed and refined through the falsification of specific hypotheses and models that are derived within that program. However, choice of research program is made on a different basis, in terms of the overall usefulness of the research generated by the central core of the program. In this context, usefulness is defined as the discovery of new facts or the novel explanation of phenomena that are known, but have not been previously understood.

Thus, Newtonian physics did not fall because of some experiments that produced results it could not explain (as a falsificationist would have us believe), nor did it fall because Einsteinian physics won some kind of cultural battle (as some naïve followers of Kuhn would have us believe). Newtonian physics fell to Einsteinian physics because Einstein's theory predicted a host of new phenomena and explained known, but previously unexplainable, phenomena, and it is in these terms that the cognitive and the Darwinian research programs have come to prevail. Each program has generated new sets of auxiliary hypotheses and, in the process of testing these hypotheses (and discarding and refining them as research proceeded), many new and unexpected phenomena have been uncovered.

\section{The cognitive research program}

It is clear that the study of cognitive processes in animals has emerged as a major field of study. There has been an explosion of interest in the approach, as indicated, for example, by the number of books devoted to the subject, beginning with Roitblat et al. (1984) through to the present (Vauclair, 1996; Roberts, 1998; Shettleworth, 1998). As the chapters in this volume demonstrate, many phenomena have been approached from the cognitive perspective. These include 
phenomena traditionally studied by ethologists (e.g. bird song; Kroodsma and Byers, Todt and Hultsch, this volume) as well as those more traditionally associated with psychologists (e.g. timing; Gibbon and Church, 1990). While the approach originated with experimental psychologists, it has also proven to be of great interest to neurophysiologists (e.g. O'Keefe and Nadel, 1978) and biologists (e.g. Real, 1994; Dukas, 1998). As the chapters in this volume demonstrate, it is a very diverse field, with investigators examining phenomena as different as spatial navigation in honey bees, birds and mammals, the perception and production of auditory signals, the comprehension and use of symbolic communication systems. This diversity is a sign of one strength of the approach the cognitive approach is applicable to a wide variety of phenomena in many different taxa. However, the field of animal cognition also appears to be fragmented, lacking a central definition. This can be seen in the many different labels that are used: animal cognition, comparative cognition, cognitive ecology, cognitive ethology, etc.

Another sign of the fragmentation of the field is the absence of a widely accepted definition of animal cognition. Many texts on animal cognition actually avoid explicit definition, tending to define cognition by example, as the study of certain types of processes such as attention, memory, etc. However, if we apply the lessons of Lakatos, we see that animal cognition is not the study of certain phenomena, it is an approach to a set of problems.

In these terms, then, how should the cognitive research program be characterized? Although it can be phrased in a number of ways, the central assumption of the cognitive program is that organisms possess some type of internal representation of the external world. Examples include cognitive maps, templates or internal images, but simpler ideas such as memories might also be included. These internal representations are related to the external world in two ways: a coding process on the input side and a relationship to behavior on the output side. Many of the alternative hypotheses we test have to do with these input-output relationships between the assumed internal representations and the external world. As Dyer (1994) put it, cognitive approaches, in contrast to noncognitive approaches "... postulate processes that organize sensory information into coherent internal models of external events, allowing the animal to respond appropriately to important stimuli even when experiencing them in novel combinations or contexts" (p. 68).

\section{Reasons for fragmentation}

\section{Disciplinary diversity}

Despite this central theme, the study of animal cognition is, as noted above, fairly fragmented. One of the reasons for this fragmentation is disciplinary di- 
versity. The students of animal cognition come from distinct disciplinary backgrounds. These different disciplines focus on animal cognition in different ways and for different reasons. Furthermore, these disciplines operate within very different research programs or paradigms making different assumptions and having different goals. That is, even in cases where researchers share the central assumptions of the cognitive program, they also are participants in other research programs, which leads to diversity of questions, approaches and goals.

\section{The relationship between human and nonhuman cognition}

One large difference among those taking a cognitive approach with animals is whether they are oriented primarily towards understanding humans, using animals as model systems, or are more oriented towards understanding the animals within a biological context. Shettleworth (1993) expressed it well, distinguishing between what she called the "anthropocentric program" and the "ecological program" (see Table 1).

\section{Specialized vs. general dichotomy}

Another problem which has haunted the study of animal cognition is the distinction between specialized and general processes. Historically, this has been a biology-psychology dichotomy. Psychologists tended to emphasize the search

Table 1. Comparison of the Anthropocentric and Ecological Programs (after Shettleworth, 1993).

\begin{tabular}{lll}
\hline Characteristic & Anthropocentric program & Ecological program \\
\hline Purpose & $\begin{array}{l}\text { Investigate continuity and } \\
\text { generality of cognitive } \\
\text { processes across species }\end{array}$ & $\begin{array}{l}\text { Investigate impact of } \\
\text { evolution on cognition; } \\
\text { understand cognition as a } \\
\text { biological phenomenon }\end{array}$ \\
$\begin{array}{l}\text { Phenomena } \\
\text { analyzed }\end{array}$ & $\begin{array}{l}\text { Animal cognition in tasks } \\
\text { modeled on what people do }\end{array}$ & $\begin{array}{l}\text { Cognitive processes that } \\
\text { animals use in nature }\end{array}$ \\
$\begin{array}{l}\text { Species compared } \\
\text { Human vs. nonhuman } \\
\text { (often implicit); } \\
\text { distantly related species }\end{array}$ & $\begin{array}{l}\text { Close relatives with } \\
\text { divergent niches; } \\
\text { distant relatives with } \\
\text { convergent niches }\end{array}$ \\
$\begin{array}{ll}\text { Relationship to } \\
\text { neuroscience }\end{array}$ & $\begin{array}{l}\text { Evidence of continuity } \\
\text { needed to justify }\end{array}$ & $\begin{array}{l}\text { Understanding evolution } \\
\text { of brain mechanisms; } \\
\text { "animal models }\end{array}$ \\
& & $\begin{array}{l}\text { specializations as modifi- } \\
\text { cations of general processes }\end{array}$ \\
\hline
\end{tabular}


for a few general process "mechanisms" that could explain a very wide variety of phenomena. In contrast, biologists interested in animal cognition tended to be interested in cases where cognitive processing seemed to be devoted to a single (or restricted set of) biological problem(s). The study of imprinting or song learning (at least in the early days) epitomized this approach.

\section{Current state of affairs}

In summary, then, the cognitive research program has proved to be an exciting, progressive one. As many of the chapters in this volume make clear, working within the cognitive paradigm has proved quite productive, leading to many exciting, often unexpected results. However, the field is characterized by a number of divisions, mostly related to different investigators working within different traditions and at different levels of analysis in an uncoordinated manner. What is needed is a more comprehensive and inclusive research program which will allow integration across these divisions.

\section{The ethological program}

It is interesting to compare this state of affairs with the dilemma facing those studying animal behavior in the 1950s and 1960s. As is the case with animal cognition today, there were many different workers from different disciplines involved, and efforts to understand animal behavior were diverse and diffuse. At least four approaches were present:

1. The "classical" ethological approach of Lorenz, which emphasizes phylogenetic relationships and genetic contributions to behavior.

2. The "British" school of ethology, which is oriented more towards adaptation.

3. The American behaviorist tradition, with its emphasis on learning and reinforcement.

4. The Schnierla-Lehrman approach, emphasizing epigenesis and experience in the broad sense.

There was considerable disagreement and confusion about how to reconcile these approaches. Especially problematic was the question of the relationship between evolutionary and mechanistic levels of analysis.

A major event in the resolution of these problems was the publication of Tinbergen's (1963) famous paper "On aims and methods of ethology." In that paper, and throughout his work and career, Tinbergen emphasized the necessity of understanding behavior at different levels, in terms of phylogeny (historical), adaptation (function), mechanism (neuroscience) and development (ontogeny). One way to express Tinbergen's position is that it called for the inte- 
grated study of these four levels of analysis. Another way to express it is that it encouraged the study of ontogeny and mechanism within a Darwinian perspective, including considerations of phylogeny and adaptation. However it is phrased, it is clear that the integrative, multilevel approach called for by Tinbergen (and others) has been successful. Today, the study of animal behavior, encompassing ethology, behavioral ecology and comparative psychology, is a much more integrated and cohesive field.

This has taken place because students of animal behavior now largely agree on a scientific research program sensu Lakatos. The central core of this program is the assumption that every behavior has an evolutionary history, a biological function, an underlying neural mechanism and a developmental history, and that these interact in many ways. This central core has produced a field of study that is a vibrant field, much different than the field of animal behavior of the 1950s and 1960s. Many of the old disciplinary distinctions have largely fallen away. Today, there are biologists in psychology departments, and psychologists in biology departments; there are truly interdisciplinary programs in which departmental or disciplinary affiliation is relatively unimportant, like those at Davis, Indiana and Nebraska. But, most important, it has proven to be a most progressive research program. Any contemporary animal behavior text will give many examples of exciting new findings generated by the multilevel, integrative approach advocated so well by Niko Tinbergen. Examples include research programs incorporating the study of sensory processes into understanding natural and sexual selection (Endler, 1980; Basolo, 1995), programs using comparative and phylogenetic approaches to understand foraging preferences (Arnold, 1981), or sexual behavior (Ryan and Rand, 1995), or programs integrating optimization models based on the concept of adaptedness with the study of behavioral mechanisms (Cuthill and Houston, 1997).

\section{Synthesis}

The major theme of this chapter is that the modern ethological approach and the cognitive approach need to be synthesized. On the one hand, the ethological program, strongly evolutionary but emphasizing the importance of mechanism and ontogeny, provides a powerful, pragmatic framework for the study of animal cognition. Those interested in cognition need to view their work in the broad integrative ethological framework. On the other hand, the cognitive research program provides a potent rubric for understanding many of the complexities that are found in the behavior of animals. Those interested in animal behavior can, in many cases, benefit from taking a cognitive approach in trying to understand the behaviors they study.

There are a number of research programs which have adopted this synthetic approach, such as those on spatial memory in seed-caching corvids (Kamil and 
Balda, 1990; Balda and Kamil, this volume) and parids (Shettleworth and Hampton, Clayton and Lee, this volume), studies of homing and navigation in birds and bees (Wiltschko and Wiltschko, Bingman et al., and Dyer, this volume) and of song learning (Todt and Hultsch, Kroodsma and Byers, De Voogt and Szekely, this volume). As the chapters in this volume demonstrate, each of the four questions Tinbergen (1963) identified can be asked about animal cognition.

\section{Physiological mechanism}

An animal's internal representations of the external world must have their physical bases in the brain, and understanding the neural bases of cognition will be an essential component of fully understanding cognition in animals (and humans). Chapters in this volume, for example, discuss the role of the hippocampus in spatial memory, and the neural bases of song learning and navigation. This work is interesting, with many important implications, but there is a basic problem at present integrating neurobiological techniques and knowledge with behavioral cognitive studies.

The problem is that our behavioral knowledge of cognitive capabilities, rudimentary though it may be in many respects, is still more advanced than our neurobiological knowledge. For example, we know that species differences in hippocampal volume, adjusted for body or total brain size, correlate with dependence on cached food in parids and corvids (Krebs et al., 1989; Sherry et at., 1989), and especially in the case of seed-caching corvids, with performance on a variety of test of spatial cognition (Basil et at., 1996). However, hippocampal volume is a very global, unsatisfactory measure. It would be most helpful if more finegrained measures could be developed. For example, work with mammals has demonstrated the existence of so-called "place neurons," neurons which fire only when the animal is in a specific place (different places having different neurons). Do seed-caching birds like nutcrackers and black-capped chickadees have more place neurons than other birds, and is that why their hippocampi are larger?

Recent developments in neurobiology indicate that many new techniques are being developed which will contribute substantially to our understanding of animal cognition by providing more detailed information about the neurobiology of cognition. For example, the positron emission tomography (PET) scans are beginning to reveal much about which parts of the brain are active during different cognitive tasks, such as recall (Schacter, 1996). Also, immunocytochemistry is beginning to provide detailed information about neural circuitry (e.g. Szekely and Krebs, 1996).

\section{Developmental processes}

The cognitive processes of animals are strongly influenced by ontogeny. This has been particularly well studied in development of song learning since 
the pioneering work of Marler (Marler and Tamura, 1964; Todt and Hultsch, Kroodsma and Byers, this volume). Seed caching and navigation provide additional examples (Clayton and Lee; Wiltschko and Wiltschko, this volume). In these cases, the ontogenetic effects seem to have clear targets. That is, the effects of varied experience, at least as they have been studied, are found in relatively specific domains. However, it is possible that ontogenetic effects may have broader, less specific impact.

Perhaps the most suggestive evidence of general effects of ontogeny comes from the work of Rosenzweig and his collaborators (e.g. Bennett and Rosenzweig, 1981). They have shown that differences in early environment have dramatic behavioral and neurobiological effects in rats, including anatomical and biochemical effects on the brain. These results imply that there is much more to be learned about the ontogeny of animal cognition, and that it will pay dividends to combine developmental, behavioral, and neurobiological approaches. Clayton and Lee's research (this volume) provides an excellent example of such work. They studied the development of spatial memory and hippocampal growth in storing and nonstoring parids. As they describe in their chapter, they found that hippocampal growth was facilitated by the opportunity to cache, but only in the caching species.

It is possible that these effects found by Clayton and Lee are indicators of more general effects. Consider what we know about ontogeny, neurobiology and spatial memory in seed-caching corvids. Young nutcrackers spend considerable time accompanying their parents recovering seeds, and engage in "playlike" cache-recovery behavior (Vander Wall and Hutchins, 1983). Dimmick (1993) found that adult, wild-caught nutcrackers recovered their caches more accurately than young nutcrackers under controlled laboratory conditions. This is consistent with the possibility of important ontogenetic effects in the development of spatial memory in nutcrackers. Basil et al. (1996) found that nutcrackers have larger hippocampi (adjusted for total brain size) than Pinyon Jays, Scrub Jays, or Mexican Jays, which are all corvids less dependent on cached food than nutcrackers. It is possible that the early experience effects suggested by Dimmick's work are expressed in increased hippocampal growth, as suggested by the findings of Basil et al.

Comparative experiments suggest even more. Balda and Kamil (1989) found that nutcrackers and Pinyon Jays recover caches more accurately than Scrub Jays. Furthermore, in a series of studies involving noncaching tests of spatial memory, Balda, Kamil and their coworkers have found consistent species differences in spatial memory that parallel the results of the comparative cache-recovery experiment (Olson, 1991; Kamil et al., 1994; Olson et al., 1995). Dimmick's (1993) results suggest that early experience may play an important role in the development of the cache site memory abilities of nutcrackers and other seed-caching corvids. These results may not be limited to cache recovery. It would be most interesting if experiments examining the behavioral 
and neurobiological effects of differential early experience, and including a battery of tests of spatial memory, were carried out. Such experiments might well reveal general effects of early experience both spatial memory and hippocampal size.

\section{Adaptive Function}

The discussion of the analysis of the ontogenetic and neurobiological substrates of cognitive processes has been relatively brief. These approaches 'e relatively well established and do not need lengthy discussion. However, analysis of cognition in an evolutionary framework, emphasizing both phylogeny and adaptation, faces some serious unresolved problems. Taking functional analysis first, we know that cognitive processes can have adaptive outcomes: remembering where food has been stored, singing effective songs, finding the way back to the hive. However, there are some special difficulties the study of behavior as adaptation. It might be worthwhile to review the methods that have been used to test ideas about behavior as adaptation and discuss the potential for the application of these methods within the cognitive paradigm.

\section{Correlational Approach}

One way to investigate the possible adaptive significance of a trait is to measure biological success (or some correlated variable) as a function of that trait. Most often, the results of such a study are in the form of a correlation. A classic case is provided by studies of the role of avian helpers at the nest. It was well known that in many species of birds, older offspring remained around the nest when subsequent broods were raised, often engaging in what eared to be helpful behavior, such as feeding the young in the new brood (Scutch, 1961). The question that arose was whether this was actually helping behavior. That is, did the behavior of the helping birds actually increase the number of young raised per nest? The first studies to investigate this issue showed that there was, in many species, a positive correlation between the presence of helpers and the number of young successfully fledged (e.g. Rowley, 1965; see Brown, 1987, esp. pp. 169173, for review).

As far as I know, this correlational approach has never been attempted any cognitive trait. The practical problem appears to be the difficulty obtaining a good measure of cognitive ability without disrupting the animal g studied. For example, it seems quite reasonable to assume that a seed-caching bird that more accurately remembers its cache sites will recover e food when needed and, therefore, survive and reproduce more successfully. However, this idea needs to be tested directly. It would be very resting to know if individual nutcrackers, Pinyon Jays or Marsh Tits with better cache site memories actually do enjoy higher degrees of biological success than those with poorer memories. However, performing this research would require capturing and test- 
ing many birds, then releasing them and collecting data on reproductive success. While possible, this approach would actually be very difficult to carry out successfully.

Another possibility might be found in cases where measures of cognitive ability might be obtainable from free-living animals. For example, Healy and Hurly (1995) have developed a method for testing hummingbirds on a spatial learning and memory task under field conditions. In essence, they used artificial feeders to set up an analog of the radial maze task widely used with rats. The free-flying hummingbirds had to keep track of which feeders in the array they had visited and avoid revisits to these emptied flowers on a subsequent visit. This is quite analogous to a problem that nectar feeders face in nature (Gill and Wolf, 1977). Healy and Hurly found not only that the birds learned the task, but that there were considerable individual differences in performance. Repeat visits to already emptied flowers can have quite significant effects on food intake (Kamil, 1978). It would be particularly interesting to see if the individual differences observed by Healy and Hurly (1995) might correlate with a direct or indirect measure of fitness, such as rate of fat accumulation during pauses in migration.

\section{Experimental approach}

Although the correlational approach can produce useful and important information, it has a basic weakness: it only produces a correlation and correlation does not prove causation. The fact that the number of young fledged is correlated with the number of helpers could be due to some third variable which correlates with both variables. For example, territorial quality could influence both factors, causing helpers to stay on better territories, which, by their very nature, also produce more young regardless of the number of helpers. This problem can be avoided by manipulating the variable of interest experimentally, with individual animals assigned to conditions at random. Then, if an effect is found, we can be more certain of the causal relationship between the trait and biological success. Thus, in the case of helpers at the nest, it is possible to identify a set of territories with equivalent numbers of helpers present and then experimentally remove helpers from some nests, selected at random. Such experimental studies have confirmed the hypothesis that, at least in some species, the presence of helpers at the nest does increase the number of young fledged (Brown et al 1982).

There are three ways that this approach could be applied to cognition.

1. Using neurobiological techniques to interfere with a cognitive ability. One way is to interfere with the cognitive ability by lesioning animals and observing the effects on free-ranging animals. Krushinskaya (1966) performed hippocampal lesions on free-ranging Eurasian Nutcrackers and found that the lesions impaired their ability to relocate their stored food. However, lesions represent a fairly crude manipulation and raise serious ethical concerns. It is possible that, 
as neurobiological techniques advance, finer and more detailed methods of interfering with cognitive abilities by disrupting the neural substrate may well become available. If so, these may offer greater promise scientifically as well as reducing the ethical concerns raised by the lesioning techniques.

2. Using a lack of the opportunity to learn as a simulation of inability to learn. For example, Hollis (1984) has examined the effects of associative learning on aggressive behavior. Male Blue Gouramis (Trichogaster trichopterus) were conditioned to a red light. Whenever the red light came on, it was followed by the appearance (behind a clear partition) of another male. Control fish received no such conditioning. In the critical test, Hollis placed a conditioned male on one side of an opaque partition; an unconditioned male on the other side. After the red light, which was visible to both fish, came on, the partition was removed. The conditioned fish won most of the ensuing aggressive encounters, showing higher levels of aggressive behavior than the controls. One way of interpreting these data is that the behavior of the control represents the behavior that might be expected from a fish exposed to the same conditioning as the experimental males, but without the ability to learn the association. In this light, these experiments demonstrate an approach to simulating the behavior of animals without specific cognitive abilities to investigate the possible adaptive value of those abilities. More recently, this work has been extended to show that when the conditioned stimulus predicted the appearance of a receptive female, conditioned male gouramis had distinct paternal advantage over nonconditioned males (Hollis et al 1997).

3. Providing special learning experience to free-ranging animals. Another possibility might be to provide special training experiences and to observe potential effects on biological success. For example, several studies of nectar-feeding birds have shown that they increase foraging efficiency by avoiding flowers which they have already emptied (Gill and Wolf, 1977; Kamil, 1978). Cole et al (1982) found that adult-caught hummingbirds could learn to avoid revisiting artificial flowers more rapidly than they could learn to revisit them. However, Wunderle and Martinez (1987) found that laboratory-raised nectar-feeding bananaquits did not show this bias, although wild-caught adults did. This suggests that the avoidance of visited flowers may be learned. It would be interesting to observe the effects of inexhaustible nectar feeders on the foraging patterns of young free-flying birds.

This approach might be well suited to research with insects. Insects show many types of learning (Papaj and Lewis, 1993) and, with their relatively short life spans, research on the lifetime fitness effects of early experience might be particularly practicable. For example, Heinrich and his collaborators (Heinrich et al., 1977; Waddington et al., 1981) have found experiential effects on flower choice by bumblebees. It might be possible to arrange various early experiences for bees, then observe the effects of these experiences on later foraging success. 


\section{Comparative approaches}

In this approach, species are chosen for study based upon their natural history and phylogeny, taking advantage of the processes of divergence and convergence. Divergence refers to differences among closely related species owing to differences in their natural histories and adaptations, while convergence refers to similarities among distantly related species owing to similarities in their natural histories and adaptations. There are many examples of the use of these strategies with nonbehavioral and behavioral traits. The classic case in behavior is the study of the effects of cliff nesting in sea birds. Most gulls nest on the ground, but a few, including Kittiwakes, nest on very narrow ledges on steep cliff faces. Many of the behaviors of Kittiwakes differ from those of groundnesting gulls in ways that seem sensibly related to cliff nesting. For example, Kittiwake adults, unlike other gulls, show weaker reactions to predators, do not remove eggshells and droppings from around nests and do not learn to recognize their young, at least in the first 4 weeks after hatching. Kittiwake chicks do not run when attacked, and show much less movement around the nest (Cullen, 1957). These appear to be reasonable adaptations to cliff nesting, but how is this adaptive hypothesis to be tested?

One way to test it would be to examine the behaviors of other cliff-nesting sea birds. If the hypothesis is correct, many similarities should be found. Studies of the Black Noddy (Cullen and Ashmole, 1963) and the Galapagos Swallow-tailed Gull (Hailman, 1965) generally supported the hypothesis. These two cliff-nesting species also diverged from their close relatives who are ground nesters in a manner similar to those by which the Kittiwake differs from its ground-nesting relatives.

The comparative strategy seems quite appropriate for empirical analysis of questions about the adaptive function of cognitive abilities. However, there is a fundamental problem that confronts the study of cognitive processes in a comparative framework, the learning-performance problem (Kamil, 1988). That is, although we are interested in measuring learning abilities or cognitive abilities in our experiments, all we are ever able to measure directly is behavior, and the behavior we observe is a function of many factors besides cognitive ability. Therefore, whenever we obtain a difference between species in their performance on a cognitive task, how can we be sure that the difference truly represents a difference in cognitive ability?

For example, Balda and Kamil (1989) found that Clark's Nutcrackers and Pinyon Jays recovered their caches more accurately than Scrub Jays in a laboratory situation. This difference might be the result of a species difference in spatial cognition but it might also be due to effects of some parameter of the experiment that was inadvertently ill-suited to Scrub Jays. It is quite possible that, under only slightly different conditions (e.g. different room layouts, motivational conditions, etc.), Scrub Jays would have performed much better. 
Bitterman (1965) was the first to point out this problem. He suggested a technique, which he called control by systematic variation, to solve it. The basic idea was to carry out a series of experiments parametrically testing the effects of each potential variable that might have adversely affected the species that performed poorly. These variables were called contextual variables (Macphail, 1985). Although logical, this idea faces a serious problem: it is impossible to test all such variables. A researcher attempting to use control by systematic variation is placed in the position of trying to prove the null hypothesis, that there are no conditions under which the species will be equivalent.

I have suggested an alternative strategy based on the concept of converging operations (Kamil, 1988). The basic idea of this strategy is to test the species in question with a battery of different tests of the same cognitive ability. If a pattern of species differences holds across a wide variety of tasks, involving different environments, this would provide fairly convincing evidence that the difference was due to the aspects that the tasks had in common, namely the cognitive ability under test.

This is the strategy we have followed in comparative studies of spatial memory in seed-caching corvids. After obtaining the species difference in cache-recovery accuracy (Balda and Kamil, 1989), we proceeded to test the species in other settings, including an open room analog of the radial maze (Kamil et al., 1994) and tests in operant chambers (Olson, 1991; Olson et al., 1995). The basic pattern of species differences held across all of these experiments. Although one could still argue for some confounding variable, it would have to be one that was present across all of these very diverse tasks.

In thinking about these results, particularly just how strong an argument they actually present for the existence of differences among these species, two weaknesses in the Kamil (1988) paper have become apparent. The first is that there is an alternative hypothesis that needs to be tested, namely that the species differences observed are not due to a specific difference in cognitive abilities, but rather to some general factor. For example, nutcrackers may simply be more adaptable to the laboratory than other species. The second is that, although the use of converging operations may weaken the argument from contextual variables, it does not eliminate it. These considerations indicate that an additional step is needed.

This additional step might be called differentiation. It involves designing an experiment to be as similar as possible to those demonstrating species differences through converging operations, but testing a different cognitive ability. In the case of the work we have done with seed-caching corvids, there was an obvious possibility, the operant tests. Olson's (1991) original demonstration of differences in an operant setting used a task known as spatial nonmatching to sample. In this task, the animal is required to remember the spatial location of a briefly illuminated spot, then later avoid pecking it. It was relatively easy to 
design an experiment virtually identical to that of Olson except that the color of the illuminated spot was what needed to be remembered, not its spatial location. When we carried out this experiment (Olson et al., 1995), we found that the ordering of the species was completely different, and that none of the species differences was significant. These data demonstrate that the differences we obtained during spatial tasks are not general across all tasks. They also rule out most contextual variables - if contextual variables were responsible for the differences originally found in spatial tasks, those same variables should have resulted in species differences in this experiment (see Lefebvre and Giraldeau, 1996, for a somewhat different approach).

Taken together, these experiments provide convincing evidence of a set of differences in cognitive abilities that correlate with a feature of natural history, dependence on stored seeds. They also demonstrate one of the major disadvantages of the comparative approach: the necessity to conduct a research program, not one or two experiments. However, hypotheses about the adaptive significance of behavior are never easy to test.

When is cognition adaptive? The problem of cost

One interesting aspect of the analysis of cognition in an adaptive framework is the exploration of the question, "When does it pay to possess a cognitive ability?." Relatively little formal theoretical or empirical work has been carried out looking at this basic question. The work that has been done, however, suggests this will be a fruitful area for further exploration. For example, Stephens (1991) has modeled the effects of within and between generational stability on the adaptedness of learning. He did this with a model in which the environment varied between good and bad states within and between generations, and learning genotypes competed with nonlearning genotypes. He found that the learning genotype would prevail only under some circumstances. Furthermore, the range of circumstances under which learners outcompeted nonlearners was more restricted when the learning mechanism had a cost associated with it.

Although the question of the cost of learning has received little formal exploration, one basic piece of information we already have tells us that cognitive abilities have costs. How do we know that? Well, first of all, the cognitive abilities of animals are limited. As Fred Dyer put it in his abstract for the symposium on the evolution of animal cognition held in Flagstaff, AZ, from which many chapters in this volume originated: "Why do animals not remember more, learn faster, or perform tasks with less error than we observe them doing?" For example, even the best Clark's Nutcracker forgets some of its cache sites, i.e. its memory ability is limited. This only makes sense if we assume that the ability to perform better, to remember more sites for instance, would entail some costs. Presumably, the development of increased ability would entail carrying around 
more neural tissue, with an accompanying increased metabolic load. This argument implies that the cost of the extra memory capacity is greater than the cost of storing some extra seeds to compensate for memory loss. Without a method for directly assessing the costs, the concept is difficult to test.

Another sort of evidence that suggests cognitive costs are the biases we find in learning, such as those shown in the well-known phenomenon of taste-aversion learning. It is much easier for many animals to learn an association between certain pairs of stimuli, such as a taste and illness for example, than between other pairs, such as a sound or a light and illness. One way to look at this situation is that the animal experiences a constant stream of stimulation. When a particularly significant event, such as illness, occurs, why does the animal's internal representation of the stimuli preceding the event not include all of the stimuli? One answer would be as suggested above: it is too expensive in terms of the neuronal substrate required. However, another answer is that inappropriate learning could occur. This is, sounds and lights are not usually reliable indicators of illness, and forming such associations might be maladaptive. This example may have broad implications: perhaps one of the costs of learning is that, under some circumstances, if certain kinds of associations, for example, are learned too easily, they will result in behavior that has negative consequences.

An example of this type involves egg recognition in birds that are subject to host parasitism. There are avian species, such as the European Cuckoo (Cuculus canorus) or the Brown-headed Cowbird (Molothrus ater), that lay their eggs in the nests of other species. Some of these hosts learn what their own eggs look like and then reject eggs that are too different (Lotem et al., 1995). However, there are potential costs associated with rejection. Rejection may result in damage to one's own eggs and there may be mistakes in identification. Therefore, we might expect that decisions of whether or not to reject eggs will be affected by environmental factors, such as the presence of host parasites. This appears to be the case (Davies et al., 1996). Taking the argument a step further, we might reasonably expect egg recognition to evolve only in species that are subject to social parasitism and that would be physically capable of removing the intruding egg from their nest.

\section{Phylogenetic history}

Last, and certainly most difficult, is the question of evolutionary history. Recent years have seen an exciting approach to this problem emerge. Interestingly, in a sense, this represents a return to the roots of ethology. One of the most important early papers in gaining acceptance for the study of behavior in biology was Lorenz's comparative study of Anatidae, in which he demonstrated that behavior could be used as a trait in addressing taxonomic issues (Lorenz, 1941). What 
Lorenz did, in that research, was to use behavioral traits to clarify a phylogeny. However, the opposite approach, using well-accepted phylogeny, in the form of a cladogram, to clarify the evolutionary history of behavioral traits is what we want to emphasize here.

While the comparative approach described above emphasized the selection of species for comparative study on the basis of ecology, the phylogenetic approach uses criteria based on phylogenetic relationship. As spelled out by a number of authors, including Brooks and McLennan (1991; see also Harvey and Pagel, 1991; Martins, 1996), the basic procedure is to map the traits of interest on to an existing phylogeny. Then, using the parsimony assumption, it is possible to draw inferences about the evolutionary history of the trait. This approach has been successfully applied to a number of behavioral traits, including McLennan's (Brooks and McLennan, 1991) work with sticklebacks and Basolo's $(1995,1996)$ research on sexual selection in Poecilliid fishes.

There are two sets of factors that limit the utility of this approach, one set general and one more specific to cognitive abilities. The general factors have to do with the use of phylogenies. Good phylogenies are often unavailable for specific groups of animals and this, of course, makes any approach that depends on having a phylogeny impossible. In addition, any phylogeny is only a hypothesis, dependent on the characters used to construct it. There are often arguments about which characters are best and there is no universal agreement on the best methods of construction. If a comparative analysis is based on an incorrect phylogeny, and we never know with certainty that any given phylogeny is correct, then it will produce mistaken conclusions.

The other set of problems concerns measurement of the relevant traits. First of all, cladistic analysis is easiest with binary traits and cognitive traits are rarely binary. Secondly, as discussed earlier, there are no standard units for the measurement of cognitive abilities. Therefore, to be even reasonably confident we have found differences in these abilities, we need to use a method of converging operations.

Although there will always be limits on the methods we use for phylogenetic analysis, at least until we have a time machine, we cannot afford to ignore questions of the evolutionary history of cognition. First of all, the results of comparative adaptive studies must be evaluated in light of phylogeny (Balda and Kamil, De Voogd and Szekely, this volume). Secondly, only a broad phylogenetic approach will reveal general trends in the evolution of cognition which can give insight into common constraints and patterns of diversification.

\section{The critical question: integration}

The really important point about Tinbergen's (1963) article was not just that all four questions can be asked and are legitimate, a point in little dispute today, at 
least among behaviorists. Nor is it that they represent different levels of analysis, not competing alternatives in much dispute among behaviorists. However, the really critical point Tinbergen made was that, in the long run, we need to integrate these questions and their answers into a coherent whole. An important corollary is that the questions complement each other in the sense that answers at one level can inform the search for answers at other levels.

There are many examples in the contemporary study of behavior that indicate the power of combining levels of analysis, or using information from one level to inform research at another level. One of the first comprehensive examples was the work of Arnold (1981). This research program combined comparative, developmental, behavior genetic and sensory approaches to develop a comprehensive picture of the evolution, function and behavioral mechanisms of foraging preferences in garter snakes. Another comprehensive example is the work of Endler $(1980,1990)$ of the relationships between sensory processes and natural selection. The value of the integrative approach for the study of animal cognition is clearly shown in many of the chapters in this book, including work on spatial memory (Clayton and Lee, this volume), on song (De Voogd and Szekely, Kroodsma and Byers, this volume), and migration (Bingman et al., this volume).

\section{The advantages of the synthetic approach}

One way we can try to capture the essence of the approach outlined here is to look at a table of its characteristics similar to that used by Shettleworth (1993) to compare the ecological and anthropocentric programs (Table 2).

A large advantage of this integrative, Tinbergian approach is that it resolves many of the difficulties that have been discussed earlier in this paper. Clearly, the integrative approach should eliminate many of the problems associated with disciplinary diversity. By including and integrating all four levels of analysis, most questions about cognition can be accommodated.

Another advantage of the synthetic approach is that, when viewed within the broad synthetic and biological context, the specialized vs. general process issue disappears as a divisive issue. In an integrative context, it is clearly a misperception to conceive of the distinction between specialized and general processes as a dichotomy. It is instructive here to look at nonbehavioral systems. In a wide variety of physiological cases, for example, there are general processes, but the exact nature and details of these processes often vary enormously within the animal kingdom, or even within the vertebrates or the mammals. That is, even very general physiological and morphological traits and systems show specialization.

Consider, for example, the problem of oxygen transport. The delivery of oxygen to the cells of the body is an essential, general problem facing many ani- 
Table 2. Characteristics of the Synthetic Approach

\begin{tabular}{ll}
\hline Characteristic & Synthetic program \\
\hline Purpose & $\begin{array}{l}\text { Use cognitive approach to increase integrative } \\
\text { understanding of animals and humans }\end{array}$ \\
Phenomena analyzed & $\begin{array}{l}\text { Any behavior where cognitive approach } \\
\text { is useful }\end{array}$ \\
Species compared & $\begin{array}{l}\text { Chosen on basis of considerations of } \\
\text { adaptation and phylogeny }\end{array}$ \\
Relationship to neuroscience & Inclusive \\
\hline
\end{tabular}

mals. In many invertebrates, oxygen is simply carried in solution in the blood or hemolymph. However, in many animals, and in almost all of the vertebrates, respiratory pigments, special compounds containing metals, are used as oxygen carriers (Schmidt-Nielsen, 1990). There are a number of different respiratory pigments in animals, distributed very systematically across the animal kingdom. In vertebrates, hemoglobin is almost universal, but there are still important differences. For example, the Bohr effect (the acid sensitivity) of hemoglobin varies widely in mammals as a function of body size, and mammals living at higher elevations show greater oxygen dissociation (affinity for oxygen) than those living at lower elevations. The point here is that, although hemoglobin may represent a general process for oxygen transport, this does not mean that it is identical in all animals, all vertebrates or even all mammals. Similar examples are widespread in terms of organs: lungs, hearts, kidneys. Even very general processes show clear evidence of specialization. Therefore, it is not useful to conceptualize biological processes and this includes cognition, as belonging to one of two categories, general or specialized. Even in the case of the most general processes, we should expect some specializations to have evolved.

There are some particularly interesting and difficult problems that need to be resolved around the issue of the relationship between general process on the one hand and specialization, especially in the sense of serving specific function, on the other. One issue is whether or not a cognitive ability that evolved in one context can be expressed in another. On the one hand, selection acts on specific outcomes. Thus, for example, any mechanism that improved the ability of a Clark's Nutcracker to remember its cache locations could be selected for, whether or not that mechanism improved other aspects of the cognitive abilities of nutcrackers, spatial or nonspatial. On the other hand, pleiotropic effects are not uncommon and the results of our comparative studies of spatial memory in seed-caching corvids shows that, in this case at least, selective effects seem to have been general, at least within the domain of spatial memory or cognition. 
Another issue is whether or not certain problems are so ubiquitous that, once they have given rise to a process, that process persists. There are physical adaptations, such as warm bloodedness or feathers, whose phylogeny demonstrates that this is quite possible. One of the possible advantages of the cognitive approach is that this approach suggests that, at least at some levels of analysis, this may be the case. As Gallistel (1990) has pointed out, certain problems - representing time and space, and detecting causation in the flow of events, for example - are indeed ubiquitous and this may help understand widespread similarities in spatial information processing and associative learning. In this context, Gallistel (1992) has formulated an interesting model for classical conditioning based on the assumption that treats the classical conditioning process as a computational mechanism evolved to solve a distinct learning problem: extracting information from a multivariate, non stationary time series.

The place of the anthropocentric approach

One view that is not easily accommodated within the synthetic approach is the "animal model" anthropocentric view, the approach that is oriented towards using animals as model systems for understanding humans. This view is so nonbiological that it is hard to see how it could fit. Consider this quotation: "The comparative psychology of cognition follows directly from the theory of evolution. As Darwin (1871) observed, it is 'highly probable that with mankind the intellectual faculties have been mainly and gradually perfected through natural selection' (p. 160)," (Terrace, 1993). This is a very clear statement in favor of taking an evolutionary view of cognition.

However, the peculiar thing about the anthropocentric approach is that, while it accepts the general Darwinian-based point of continuity between humans and other animals, it seems to accept very little else about the Darwinian perspective. For example, Terrace (1993) reviews studies of series learning in pigeons and monkeys. The main reason that Terrace is interested in this paradigm is to discover the properties of serial learning in the absence of language, as if the only important difference between pigeons and humans, or even monkeys and humans, is language. Another indication of the nonbiological thinking typical of this approach is the use of the word phylogeny. Terrace concludes that serial learning “... appears to be phylogenetically quite old" (p. 162). However, comparative biologists understand the dangers in using comparisons among so few disparate species to make such assertions. Although Terrace's research on serial learning is well executed and clever, and has produced interesting results that are informative about animal cognition, it is clearly not Darwinian in the contemporary sense of the term.

Although the anthropocentric approach may have its successes, it is inherently limited as long as it fails to take into account the biological nature of the animals that are studied. Wasserman (1997) has recently suggested that the an- 
thropocentric and ecological-evolutionary approaches need not be viewed as conflicting with one another because each asks a different question. He argues that "... the parallel use of both strategies should make for a powerful and complementary alliance for the future study of animal cognition" (Wasserman, 1997, p. 128). While the potential does exist for such an alliance, it will require both schools to be sophisticated about both evolutionary and proximate, mechanistic factors (just as Tinbergen suggested in 1963).

It is important to realize that, although it is not human-centered, the synthetic approach is relevant to understanding human cognition. Certainly, the study of cognitive processes in animals should contribute to our understanding of human cognition. However, this is more likely to develop if we understand cognition in a broader, more biological framework than that typically used by proponents of the anthropocentric approach. In this context, there is another version of the anthropocentric approach which is more in accord with the synthetic approach. This version uses comparative strategies with humans and closely related primates to try to understand how human abilities evolved (e.g. Povinelli, 1993).

Many examples of the advantages of such a framework can be found. For example, medical research has certainly utilized the "animal model," anthropocentric approach quite heavily, and with success. None the less, recent work on "Darwinian medicine" has shown that even more insight can be gained by applying Darwinian ideas to the study of many topics in medicine, including epidemiology, pregnancy, host-parasite interactions, and infectious disease (Nesse and Williams, 1991; Ewald, 1994).

Other potential examples come from the emerging field of evolutionary psychology (Barkow et al., 1992). One interesting example of how a broad evolutionary approach might be applied to human cognition comes from studies of social cognition. It has been hypothesized that one of the arenas for the evolution of intelligence has been the social arena (e.g. Humphrey, 1976; Cheney and Seyfarth, 1990). In that case, one might expect that humans could solve social problems most readily. There is also evidence that, when the same logical problem is presented in a social context, people find it easier to solve than when the same logical problem is presented in an abstract, nonsocial context (Cosmides, 1989).

\section{Conclusions}

This chapter has outlined a general research program for the study of cognition in animals, an approach which the following chapters of this book demonstrate is well under way. This program synthesizes two scientific research programs, the cognitive and the ethological. It applies the approach exemplified by Niko 
Tinbergen, emphasizing the importance of studying evolutionary and mechanistic levels of explanation in a single, integrative framework, to the study of cognition. What should this approach be called? There are many possibilities, some of which are listed below.

\section{Comparative cognition?}

One label that is sometimes used for animal cognitive work is comparative cognition, but it is not appropriate for the approach outlined here. Not all work called for in the synthetic approach needs be comparative; much will not be. Furthermore, current usage of the phrase is inappropriate. It has, for many, come to refer to the anthropocentric approach, emphasizing using information about human cognitive processes in the design of animal studies of cognition.

\section{Cognitive ecology?}

Another approach has been labeled cognitive ecology. Real (1993; also Dukas, 1998) has popularized this term, and used it in a manner very similar to much of what has been proposed here. However, the term ecology implies an exclusively adaptive, functional approach, and tends to de-emphasize mechanistic and ontogenetic levels of analysis as well as considerations of phylogeny.

\section{Evolutionary cognition? Cognitive biology?}

The potential list goes on and on. However, it seems obvious that, in terms of the basic philosophy of the approach and the methods it gives rise to, there is only one appropriate label for this field: cognitive ethology. This label succinctly captures the two approaches being synthesized, giving appropriate recognition to its historical precursors.

There is only one reason not to adopt this label: it has been pre-empted by Don Griffin and others (e.g. Griffin, 1976, 1978; Ristau, 1991; Bekoff and Allen, 1997), defining cognitive ethology in terms of subjective experience: awareness, consciousness, etc. Many of us working on animal cognition find this term objectionable for many reasons; so objectionable that we completely avoid using the term. One of the reasons it is objectionable is that much of the argument has focused on attempting to prove the existence of these internal states and the nature of some of these arguments is unacceptable. In particular, many of Griffin's arguments are so weak and anecdotal that they remind one of nothing more than Paley's (1851) arguments for the existence of a creator, natural theology based on the argument from design (Blumberg and Wasserman, 1995).

However, this dislike for Griffin's definition does nothing to diminish the fact that cognitive ethology is the most historically appropriate label for the ap- 
proach outlined here. If workers in this field adopt the term cognitive ethology, a new definition will replace Griffin's. If this takes place, it will challenge those who hold to Griffin's definition to become a subfield of cognitive ethology, confronting the Lakatos definition of a progressive research program. Including postulated internal states in models of behavior is nothing new nor is it objectionable. The test of such models is not truth but usefulness. Do they generate new predictions or insights which have utility? This is the challenge which the proponents of animal awareness must meet. The issue is not proving that animals have minds, it is demonstrating that making the awareness (or consciousness) assumption leads to exciting new questions and discoveries.

Meanwhile, the term cognitive ethology should be adopted to describe the field that synthesizes the Darwinian perspective of Tinbergen and contemporary ethology with the cognitive perspective of psychology. Maybe, in the long run, the difference between assuming animals have internal representations and assuming they have awareness is relatively minor. Future research should determine this issue. Scientists adopting a synthetic approach to animal cognition would do well to settle on the term cognitive ethology for the broad, biological study of cognitive processes. Cognitive ethology is the phrase that most accurately and appropriately describes the science that many of us do.

\section{Acknowledgments}

I thank Russ Balda, Jennifer Templeton, Alan Bond, Kristy Gould-Beierle, Brett Gibson and Chris Cink for stimulating discussions and suggestions during the preparation of this manuscript, and Sara Shettleworth for her very insightful comments on an earlier draft of this chapter. Preparation of this paper was supported by NSF grants IBN 9421807 and IBN 9631044.

\section{References}

Arnold, S. J. (1981) The microevolution of feeding behavior. In Kamil, A. C. and Sargent, T. D. (eds) Foraging behavior: Ecological, ethological and psychological approaches. New York: Garland STPM Press, pp. 409-454.

Balda, R. P. and Kamil, A. C. (1989) A comparative study of cache recovery by three corvid species. Animal. Behav. 38, 486-495.

Barkow, J. H., Cosmides, L., and Tooby, J. (eds) (1992) The Adapted Mind: Evolutionary Psychology and the Generation of Culture. New York: Oxford University Press.

Basil, J. A., Kamil, A. C., Balda, R. P., and Fite, K. V. (1996) Differences in hippocampal volume among food-storing corvids. Brain Behav. Evol. 47, 156-164. 
Basolo, A. L. (1995) Phylogenetic evidence for the role of a pre-existing bias in sexual selection. Proc. Roy. Soc. Lond. B 259, 307-311.

Basolo, A. L. (1996) The phylogenetic distribution of a female preference. Syst. Biol. 45, 290-307.

Bekoff, M. and Allen, C. (1997) Cognitive ethology: Slayers, skeptics and proponents. In Mitchell, R. W., Thompson, N. S. and Miles, H. L. (eds) Anthropomorphism, Anecdotes, and Animals. Albany, NY: State University of New York Press.

Bennett, E. L. and Rosenzweig, M. R. (1981) Behavioral and biochemical methods to study brain responses to environment and experience. In Lahue, R. (ed.) Methods in Neurobiology, Vol. 2. New York: Plenum Press, pp. 101-141.

Bitterman, M. E. (1965) Phyletic differences in learning. Am. Psychol. 20, 396- 410.

Blumberg, M. S. and Wasserman, E. A. (1995) Animal mind and the argument from design. Am. Psychol. 50, 133-144.

Brooks, D. R. and McLennan, D. A. (1991) Phylogeny, Ecology, and Behavior. Chicago: University of Chicago Press.

Brown, J. L. (1987) Helping and Communal Breeding in Birds: Ecology and Evolution. Princeton, NJ: Princeton University Press.

Brown, J. L., Brown, E. R., Brown, S. D., and Dow, D. D. (1982) Helpers: Effects of experimental removal on reproductive success. Science 215, 421-422.

Cheney, D. L. and Seyfarth, R. M. (1990) How Monkeys See the World. Chicago: University of Chicago Press.

Cole, S., Hainsworth, F. R., Kamil, A. C., Mercier, T., and Wolf, L. L. (1982) Spatial learning as an adaptation in hummingbirds. Science 217, 655657.

Cosmides, L. (1989) The logic of social exchange: Has natural selection shaped how humans reason? Studies with the Wason task. Cognition 31, 187-276.

Cullen, E. (1957) Adaptations in the Kittiwake to cliff-nesting. Ibis 99, 275- 302.

Cullen, J. M. and Ashmole, N. M. P. (1963) The black noddy Anous tenuirostris on Ascension Island. Part 2, Behavior. Ibis 103, 423-446.

Cuthill, I. C. and Houston, A. I. (1997) Managing time and energy. In Krebs, J. R. and Davies, N. B. (eds) Behavioural Ecology: An Evolutionary Approach 4th edn. Oxford: Blackwell, pp. 97-120.

Darwin, C. (1871) The Descent of Man, and Selection in Relation to Sex. London: J. Murray.

Davies, N. B., Brooke, M. d. L., and Kacelnik, A. (1996) Recognition errors and probability of parasitism determine whether reed warblers should accept or reject mimetic cuckoo eggs. Proc. Roy. Soc. Lond. B 263, 925-931. 
Dimmick, C. R. (1993) Life history and the development of cache-recovery behaviors in Clark's Nutcracker. PhD thesis, Northern Arizona University.

Dukas, R. (ed.) (1998) Cognitive Ecology: The Evolutionary Ecology of Information Processing and Decision Making. Chicago: University of Chicago Press (in press).

Dyer, F. C. (1994) Spatial cognition and navigation in insects. In Real, L. A. (ed.) Behavioral Mechanisms in Evolutionary Ecology. Chicago: University of Chicago Press, pp. 66-98.

Endler, J. A. (1980) Natural selection on color patterns in Poecilia reticulata. Evolution 34, 76-91.

Endler, J. A. (1990) On the measurement and classification of colour in studies of animal colour patterns. Biol. J. Linnean Soc. 41, 315-352.

Ewald, P. W. (1994) Evolution of Infectious Disease. Oxford: Oxford University Press.

Gallistel, C. R. (1990) The Organization of Learning. Cambridge, MA: MIT Press.

Gallistel, C. R. (1992) Classical conditioning as a nonstationary, multivariate time series analysis: A spreadsheet model. Behav. Res. Meth. Instrum. Comput. 24, 340-351.

Gibbon, J. and Church, R. M. (1990) Representation of time. Cognition 37, 23-54.

Gill, F. B. and Wolf, L. L. (1977) Nonrandom foraging by sunbirds in a patchy environment. Ecology 58, 1284-1296.

Griffin, D. R. (1976) The Question of Animal Awareness: Evolutionary Continuity of Mental Experience. New York: Rockefeller University Press.

Griffin, D. R. (1978) Prospects for a cognitive ethology. Behav. Brain Sci. 1, 527-538.

Hailman, J. P. (1965) Cliff-nesting adaptations in the Galapagos swallow-tailed gull. Wilson Bull. 77, 346-362.

Harvey, P. H. and Pagel, M. D. (1991) The Comparative Method in Evolutionary Biology. New York: Oxford University Press.

Healy, S. D. and Hurly, T. A. (1995) Spatial memory in rufous hummingbirds (Selasphorus rufus): A field test. Anim. Learn. Behav. 23, 63-68.

Heinrich, B., Mudge, P., and Deringis, P. (1977) A laboratory analysis of flower constancy in foraging bumblebees: Bombus ternarius and B. terricola. Behav. Ecol. 2, 247-266.

Hollis, K. L. (1984) The biological function of Pavlovian conditioning: The best defense is a good offense. J. Exp. Psycho I. Anim. Behav. Proc. 10, 413-425.

Hollis, K. L., Pharr, V. L., Dumas, M. J., Britton, G. B., and Field, J. (1997) Classical conditioning provides paternity advantage for territorial male blue gouramis (Trichogaster trichopterus). J. Comp. Psychol. 111, 219-225. 
Humphrey, N. K. (1976) The social function of intellect. In Bateson, P. P. G. and Hinde, R. A. (eds) Growing Points in Ethology. Cambridge: Cambridge University Press, pp. 303-318.

Kamil, A. C. (1978) Systematic foraging by a nectar-feeding bird, the Amakihi (Loxops virens). J. Comp. Physiol. Psychol. 92, 388-396.

Kamil, A. C. (1988) A synthetic approach to the study of animal intelligence. In Leger, D. W. (ed.) Comparative Perspectives in Modern Psychology: Nebraska Symposium on Motivation, Vol. 35. Lincoln, NE: University of Nebraska Press, pp. 230-257.

Kamil, A. C. and Balda, R. P. (1990) Spatial memory in seed-caching corvids. In Bower, G. H. (ed.) The Psychology of Learning and Motivation, Vol. 26. New York: Academic Press, pp. 1-25.

Kamil, A. C., Balda, R. P., and Olson, D. J. (1994) Performance of four seedcaching corvid species in the radial-arm maze analog. J. Comp. Psychol. 108, 385-393.

Krebs, J. R., Sherry, D. E, Healy, S., Perry, V., and Vaccarino, A. (1989) Hippocampal specialization of food-storing birds. Proc. Natl. Acad. Sci. USA 86, 1388-1392.

Krushinskaya, N. (1966) Some complex forms of feeding behaviour of nutcracker Nucifraga caryocatactes, after removal of old cortex. Zh. Evol. Biochim. Fisiol. II, 563-568.

Kuhn, T. (1970) The Structure of Scientific Revolutions, 2nd edn. Chicago: University of Chicago Press.

Lakatos, I. (1974) The Methodology of Scientific Research Programs. Cambridge: Cambridge University Press.

Lefebvre, L. and Giraldeau, L. (1996) Is social learning an adaptive specialization? In Heyes, C. M. and Galef, B. G. (eds) Social Learning in Animals: The Roots of Culture. San Diego: Academic Press, pp. 107- 128.

Lorenz, K. (1941) Comparative studies on the behaviour of the Anatinae. J. Ornithologica 89, 194-294.

Lotem, A., Nakamura, H., and Zahavi, A. (1995) Constraints on egg discrimination and cuckoo-host co-evolution. Anim. Behav. 49, 1185- 1209.

Macphail, E. M. (1985) Vertebrate intelligence: The null hypothesis. In Weiskrantz, L. (ed.) Animal Intelligence. Oxford: Clarendon Press, pp. 37-50.

Marler, P. and Tamura, M. (1964) Culturally transmitted patterns of vocal behavior in sparrows. Science 164, 1483-1486.

Martins, E. P. (ed.) (1996) Phylogenies and the Comparative Method in Animal Behavior. New York: Oxford University Press.

Nesse, R. M. and Williams, G. C. (1994) Why We Get Sick. New York: Times Books. 
O'Keefe, J. and Nadel, L. (1978) The Hippocampus as a Cognitive Map. Oxford: Clarendon Press.

Olson, D. (1991) Species differences in spatial memory among Clark's nutcrackers, scrub jays and pigeons. J. Exp. Psychol. Anim. Behav. Proc. 17, 363-376.

Olson, D. J., Kamil, A. C., Balda, R. P., and Nims, P. J. (1995) The performance of four seed-caching corvids in operant tests of nonspatial and spatial memory. J. Comp. Psychol. 109,173-181.

Paley, W. (1851) Natural Theology: Or, Evidences of the Existence and Attributes of the Deity, Collected from the Appearances of Nature. London: Gould \& Lincoln.

Papaj, D. R. and Lewis, A. C. (eds) (1993) Insect Learning: Ecological and Evolutionary Perspectives. New York: Chapman \& Hall.

Platt, J. R. (1964) Strong inference. Science 146, 347-353.

Povinelli, D. J. (1993) Reconstructing the evolution of mind. Am. Psychol. 48, 493-509.

Real, L. A. (1993) Toward a cognitive ecology. Trends Ecol. Evol. 8, 413-417.

Real, L. A. (1994) Information processing and the evolutionary ecology of cognitive architecture. In Real, L. A. (ed.) Behavioral mechanisms in evolutionary ecology. Chicago: University of Chicago Press, pp. 99-132.

Ristau, C. A. (ed.) (1991) Cognitive Ethology: The Minds of Other Animals; Essays in Honor of Don Griffin. Hillsdale, NJ: Lawrence Erlbaum Associates.

Roberts, W. A. (1998) Principles of Animal Cognition. Boston: McGraw Hill.

Roitblat, H. L., Bever, T. G., and Terrace, H. S. (1984) Animal Cognition. Hillsdale, NJ: Lawrence Erlbaum Associates.

Rowley, I. (1965) The life history of the superb blue wren, Malareus cyaneus. Emu 64, 251-297.

Ryan, M. J. and Rand, A. S. (1995) Female responses to ancestral advertisement calls in tungara frogs. Science 269, 390-392.

Schacter, D. L. (1996) Searching for Memory: The Brain, the Mind, and the Past. New York: Basic Books.

Schmidt-Nielsen, K. (1990) Animal Physiology: Adaptation and Environment, 4th edn. Cambridge: Cambridge Press.

Sherry, D. E, Vaccarino, A. L., Buckenham, K., and Herz, R. (1989) The hippocampal complex of food-storing birds. Brain Behav. Evol. 34, 308-317.

Shettleworth, S. J. (1993) Varieties of learning and memory in animals. J. Exp. Psychol. Anim. Behav. Proc. 19, 5-14.

Shettleworth, S. J. (1998) Cognition, Evolution and Behaviour. Oxford: Oxford University Press (in press).

Skutch, A. E (1961) Helpers among birds. Condor 63, 198-226. 
Stephens, D. W. (1991) Change, regularity and value in the evolution of animal learning. Behav. Ecol. 2, 77-89.

Szekely, A. D. and Krebs, Jr. (1996) Efferent connectivity hippocampal formation of the zebra finch (Taenopygia guttata): An anterograde pathway tracing study using Phaseolus vulgaris leucoagglutinin. J. Comp. Neurol. 368, 198-206.

Terrace, H. S. (1993) The phylogeny and ontogeny of serial memory: List learning by pigeons and monkeys. Psychol. Sci. 4, 162-169.

Tinbergen, N. (1963) On aims and methods of ethology. Z. Tierpsychol. 20, 410- 433.

Vander Wall, S. B. and Hutchins, H. E. (1983) Dependence of Clark's nutcracker (Nucifraga columbiana) on conifer seeds during the postfledgling period. Can. Field Naturalist 97, 208-214.

Vauclair, J. (1996) Animal Cognition: An Introduction to Modern Comparative Psychology. Cambridge, MA: Harvard University Press.

Waddington, K. D., Allen, T., and Heinrich, B. (1981) Floral preferences of bumblebees (Bombus edwardsii) in relation to intermittent versus continuous rewards. Anim. Behav. 29,779-784.

Wasserman, E. A. (1997) The science of animal cognition: Past, present and future. J. Exp. Psychol. Anim. Behav. Proc. 23, 123-135.

Wunderle, J. M., Jr., and Martinez, J. S. (1987) Spatial learning in the nectarivarous bananaquit: Juveniles vs. adults. Anim. Behav. 35, 652-658. 